\title{
A CENA DAS MINAS: DINÂMICAS DE GÊNERO NAS CENAS MUSICAIS DO PUNK E DO HARCORE EM SÃO PAULO
}

\author{
LETÍCIA NOGUEIRA SOUSA ${ }^{1}$
}

\begin{abstract}
Resumo: Tendo em vista a história do punk e hardcore em São Paulo, bem como as transformações ocorridas na contemporaneidade diante de um cenário de manifestação e contestação cada vez maior em torno das demandas sobre as questóes de gênero, esse artigo pretende examinar a cena musical que se estrutura em torno do evento Maria Bonita Fest, festival cultural realizado por mulheres ligadas ao punk e ao hardcore em São Paulo. A partir desse estudo de caso, tenta-se compreender como as cenas punk e hardcore, que se pretendiam contestadoras em sua origem, acabam por reproduzir estruturas de opressão da sociedade. Nesse sentido, a proposta é perceber como as mulheres e outros grupos subalternizados são incorporados (ou não) nesses espaços, e quais são as estratégias possíveis desenvolvidas por esses grupos a fim de reivindicarem um lugar dentro desses movimentos, formando uma cena das "minas".
\end{abstract}

Palavras-chave: Cenas Musicais; Identidade; Gênero; Punk; Hardcore.

\section{$1 \quad$ INTRODUZINDO O OBJETO}

No primeiro momento do artigo apresentaremos a cena ${ }^{2}$ punk e hardcore comum, a fim de apreender quais características desses espaços fizeram com que houvesse uma articulação para a formação de uma cena de minas, observando como as mulheres e outros grupos subalternizados são incorporados (ou não). Posteriormente, apresentaremos as mulheres com relação a essa cena padrão, levando em consideração como se colocam as dinâmicas de gênero e raça. Por fim, adentraremos a cena das minas do punk e hardcore em São Paulo, observando como essa se configura utilizando de artefatos da cena comum para contestar a pró-

1 Graduanda no Bacharelado em Ciências e Humanidades do Centro de Engenharia, Modelagem e Ciências Sociais Aplicadas da Universidade Federal do ABC.

sousa.leticia@aluno.ufabc.edu.br

2 Will Straw entende "cena como as esferas circunscritas de sociabilidade, criatividade e conexão que tomam forma em torno de certos tipos de objetos culturais no transcurso da vida social desses objetos". (JANOTTI JÚNIOR, 2012, p. 9). 
pria cena em si como a sociedade em geral. Analisaremos as dinâmicas identitárias ligadas ao gênero e a racialidade a partir de ações político-culturais alternativas que rompam com padróes tradicionais do punk e hardcore no Brasil, marcadas pela presença majoritária de homens e no hardcore principalmente homens brancos.

Para tal, por intermédio da etnografia, analisaremos a cena musical do Maria Bonita Fest que se configura como uma coletiva punk e hardcore antifascista, feminista, com ênfase na cultura underground ${ }^{3}$. Uma coletiva, ou coletivo "é um campo de troca privilegiado, uma concentração de encontros de intensidade distinta”. (MIGLIORIN, p. 309, 2012). Nesse contexto, $\mathrm{O}$ MBF refere-se a uma organização coletiva que visa, empoderar e visibilizar as mulheres na cena contracultural. Dessa forma, foram realizadas algumas visitas de campo em eventos impulsionados pelo Maria Bonita Fest, que tem formato itinerante, com edições intermitentes ${ }^{4}$, a fim de perceber as dinâmicas da cena musical in loco. O trabalho de campo é de grande importância, pois a experiência da observação participante permite captar a percepção do nativo, essencial para uma visão completa do universo dos mesmos (URIARTE, 2012, p. $4)$.

No dia 10 de março, compareci ao ensaio da banda Gulabi, e segui com elas até a "Marcha de Mulheres da Periferia". Já no dia 13 de abril, estive no lançamento da demo "Pistolar Y Pogar", da banda Lili Carabina e por fim, no evento "Punk pelo espaço do saber" no dia 25 de maio. As entrevistas ocorreram pessoalmente durante o campo e por meio digital, as entrevistadas foram mulheres cisgênero participantes das cenas em questão que escolheram a forma que gostariam de ser citadas na pesquisa.

As entrevistadas foram as integrantes da banda Gulabi: Caroline Rocha (Baixista), May (Baterista), Pogs (Guitarrista), também as organizadoras do Maria Bonita que participam da mesma banda, Maia (Vocalista/Baixista Lili Carabina), Cibele (Vocalista). Da banda Lili Carabina, Júlia (Guitarrista) e Maia. As entrevistas duraram em média quarenta minutos. Ademais, por meio digital, entrevistei a banda Charlotte Matou Um Cara e individualmente a Nina, guitarrista da mesma banda, do mesmo modo entrevistei a banda Sapataria e

3 A palavra underground pode ser traduzida como "abaixo do solo", "subterrâneo", esse universo consiste em ser contrário a ideologia do amplo consumo, divulgando seus conteúdos de forma alternativa. (FILHO; JANOTTIJUNIOR, 2006, p. 8-9).

4 Durante o período de pesquisa (out./2018 a ago./2019) não ocorreram eventos especificamente do Maria Bonita Fest, pois a coletiva estava se organizando de outras formas, trabalhando no tributo à banda Bulimia, que no momento está na fase de mixagem e masterização. 
também a Cah, guitarrista das bandas Bandido da Luz Vermelha, Matricis e Punho de Mabin.

O conceito de cenas musicais nos permite analisar o objeto de pesquisa em questão, os discursos que o percorre ou percorreram para que tenha surgido a necessidade da articulação feminina contestando espaço, a partir disso, possibilitando discutir a ação das mulheres e mulheres negras nesses ambientes através das suas clivagens de gênero e de raça.

Luciana Xavier Oliveira (2018) faz uma colocação no que tange as cenas musicais, que acredito ser fundamental para as cenas que estamos tratando aqui, destacando a importância de se analisar as cenas como processos que se desenvolvem e se reconfiguram a partir de interesses, práticas, compromissos, identidade e aspirações diferentes (OLIVEIRA, L., 2018, p. 32) para que assim sejam compreendidas da melhor maneira, também como uma oportunidade para a configuração de um circuito alternativo produtivo e como uma estratégia político-cultural independente, que se propõe a ser um espaço para a afirmação e visibilidade das mulheres, para discutir questóes de gênero e poder, tanto dentro da cena punk, quanto na sociedade em geral.

Segundo o consenso de vários autores, o punk teve grande repercussão inicial na Inglaterra, por volta da década de 70, diante de um cenário de crise e desemprego (KEMP 1993; BIVAR, 1994; CAIAFA, 1996; NETO, 2004; ROSSETTI e JUNIOR, 2015; VIEIRA, 2016). A música tinha uma postura agressiva, violenta, no modo de execução e criação das letras, sem contar com o visual que também agredia a sociedade acostumada com o movimento anterior, o hippie. Como observa Gumes, em seu artigo Marcas Sonoras Juvenis (2004):

O país vivia em recessão e sem espaço para a juventude, principalmente a dos subúrbios operários ingleses, excluída do sistema. A Inglaterra "sem futuro" tornouse o ambiente propício para trazer à tona uma identidade juvenil, ancorado por um novo tipo de música: o punk rock. Dando um basta ao slogan paz e amor, em 1976, o Movimento Punk vociferava slogans como "No Future" ou "Faça Você Mesmo", e fomentou uma nova onda rebelde e um novo mercado de consumo: o independente. Em garagens, galpóes, no fundo do quintal surgiam bandas (Sex 
A Cena das Minas: dinâmicas de gênero nas cenas musicais do Punk e do Hardcore em São Paulo

Pistols, Clash), fanzines ${ }^{5}$ (Sniffing Glue), revistas, dando voz às ideias anarquistas.

(GUMES, 2004, p. 8)

Com relação ao hardcore, seu surgimento se deu a partir da necessidade de aprimorar o punk nos anos 1980, que estava sendo desvirtuado pela mídia, que os correlacionavam somente com a "moda" ou como jovens violentos e perigosos. Algumas bandas foram para grandes gravadoras, essas foram chamadas de "traidoras do movimento", daí em diante, com o título de "New Wave” e em colaboração com a mídia, o que antes era punk foi vendido com esse novo nome (BIVAR,1982 p.76). O punk ressurge no fim dos anos 1980 mais politizado, mais próximo do anarquismo, com isso, aparece o hardcore, que pode ser considerado uma vertente do punk, sobre o mesmo aponta Caiafa:

A força com que, em 81, o punk reaparece (bandas por toda parte, em todo o mundo) faz apostar numa potência sua de renovar inesperadamente o desafio. E o som agora é muito mais rápido, com músicas brevíssimas. É o hard-core. (CAIAFA, 1995, p. 10).

É importante ressaltar que em algumas vertentes o punk está associado a corrente anarquista que "rompe com o governo constituído e prega a igualdade entre os homens, ou seja, parte do princípio de igualdade, no qual todos exercem a cidadania e são responsáveis pelo seu espaço na sociedade com direitos e deveres" (O'HARA, 2005, apud ROSSETTI e JUNIOR, 2015, p. 8-9). Mesmo com essa ideologia, o punk e o hardcore, acabam por reproduzir muitas vezes o que está imposto na sociedade em suas cenas. Maia, organizadora do Maria Bonita Fest, uma coletiva punk hardcore que se define como antifascista, feminista, com ênfase na cultura underground afirma:

Por mais que o meio bata tanto na tecla de ser libertário, anarquista esquerdista e pá, pá, pá, cê vê a mesma ignorância em relação à etnia, e identidade de gênero e gênero, do que o resto da sociedade brasileira, apesar de ser um espaço que se denomina conscientizado, politizado, de esquerda, e tal. (Maia, organizadora do Maria Bonita Fest, Vocalista da banda Gulabi, Baixista da banda Lili Carabina, 2019) ${ }^{6}$.

5 Dentro da contracultura é comum a produção de "fanzines" (revista de fãs). Feitos de forma indepen dente tem por intuito manifestar ideias e compartilhá-las.

6 Informação Verbal: Conversa com pesquisadora por redes sociais. Marcas de oralidade foram mantidas. 
Cibele, também organizadora do Maria Bonita Fest e vocalista da banda Gulabi, ao falar de como surgiu o Maria Bonita, explicita as estruturas machistas da cena e que essas influenciaram para a articulação das mulheres buscando criar nessa mesma cena um espaço de mulheres, para que assim, possam abordar suas questóes, participar ativamente e sentir-se bem em um ambiente que antes, mesmo que de maneira enrustida, as oprimiam.

\begin{abstract}
A cena é machista, ela tanto é que foi daí que surgiu a Maria Bonita, tava toda vez assim em um espaço onde você tinha abusador, estuprador, desfilando pelo lugar, isso é revoltante sabia, porque enquanto eles estão ali cumprimentando todo mundo, os brothers deles, as mulheres que foram vítimas de certos abusos e assédios e etc, estão em casa deixando de participar de um espaço de discussão, de troca de ideias, e de lazer também, estão em casa, ou não sei onde, deixando de participar dessa cena com a qual ela se identifica porque elas não querem trombar um cara que foi zoado de alguma forma com elas. Então isso pra nós é super-revoltante, e foi por isso que a gente cansada desse tipo de situação criou o Maria bonita, pra fazer do nosso jeito pra ser bem pé na porta assim, esses caras não vão entrar. A gente não proíbe que homens participem, mas eles têm que saber qual é o lugar deles que definitivamente não é na frente, as mulheres são na frente, é isso. (Cibele, organizadora do Maria Bonita Fest, vocalista da banda Gulabi, 13, abr. 2019). ${ }^{7}$
\end{abstract}

\title{
3 MULHERES NA CENA PUNK E HARDCORE
}

Após a leitura de obras que tratam de ambas as cenas, nota-se uma insuficiência nas discussões sobre a presença de mulheres. Há a possibilidade de que elas estivessem sendo colocadas no coletivo quando se tratavam dos “jovens”, outra possibilidade seria que elas foram vistas como "minas dos caras", e não como parte do movimento, como cita Marques (2013, p. 6):

Dentro do punk, as associações com o que é definido como masculino, em nossa sociedade, ficam ainda mais visíveis: a música e o visual são extremamente agressivos, punk tem a ver com violência, com choque, com enfrentamento; essas características foram em nossa ocidentalidade, forçadas e reforçadas como ligadas ao que é masculino. Não era de se estranhar, portanto, que, no início do punk e ainda nas décadas de 1970 e 1980 surgissem poucas mulheres na cena. (MARQUES, 2013, p. 5) 
Para Wivian Weller em seu artigo A presença feminina nas (sub) culturas juvenis (2005) ao tratar da invisibilidade da presença feminina nesse contexto, a autora questiona se o sexo feminino realmente forma uma minoria no movimento hip hop, em outros movimentos estético-musicais, como o punk, ou em outras formas associativas como as galeras ou gangues. Ela também faz uma leitura que possibilita que a invisibilidade feminina possa ser relacionada com a forma em que algumas culturas juvenis são vistas como protesto e resistência, e as culturas juvenis femininas "parecem" não demonstrar esse tipo de atitude. Já para a autora Addie Shrodes em The 'Race Riot' Within and Without 'The Grrrl One'; Ethnoracial Grrrl Zines' Tactical Construction of Space (2012) com o surgimento e domínio do hardcore nos anos 1980 o feminino no punk foi cada vez mais marginalizado:

\begin{abstract}
O assédio sexual e as provocações não eram incomuns quando as mulheres tocavam em bandas (Meltzer, 9). Para o público, a estética de dança "moshing" do punk hardcore, durante a qual os participantes se chocam violentamente, especialmente expulsando as mulheres. Moshing muitas vezes relegou os membros do público feminino para o lado de fora durante os shows hardcore de punk - o que exemplifica como artistas masculinos e uma estética masculina começaram a dominar a cena punk. (SHRODES, 2012, p.20).
\end{abstract}

Ribeiro, Costa e Santiago no que diz respeito a invisibilidade da mulher no punk dizem que:

O que foi notório no início dos anos 1990 é que as relaçôes de gênero na cultura punk em si não foram problematizadas e acabaram reproduzindo desigualdades que, em tese, deveriam ser contestadas. A prova disso é uma maior quantidade de garotos do que garotas nessa cena. (RIBEIRO; COSTA; SANTIAGO, 2012, p. 228).

Segundo Butler (2011), em diálogo com Beauvoir, a categoria "mulher" se refere a uma ideia histórica e não um fato natural, o que salienta nitidamente a distinção entre o sexo, como uma realidade biológica, e o gênero, como uma interpretação cultural ou significação dessa realidade. A construção de gêneros e sexualidades, segundo Louro (2008), se dá por meio de várias aprendizagens e práticas, produzidas por um conjunto abundante de instâncias socioculturais, de maneira explícita ou ilusória, em um processo inacabado. Sendo assim, gêneros e sexualidades são construções históricas, culturais e sociais. O homem branco heterossexual ficou em posição de ter o poder da verdade sobre os demais, como afirma Méllo (2012, p. 199) "a heterossexualidade é o modelo de normalidade. Fora desse modelo temos patologi- 
as: um corpo mal tatuado pela natureza ou um ser que deseja mudar a tatuagem natural”. As mulheres, assim, são convertidas em um segundo sexo, enquanto gays, lésbicas, bissexuais são compreendidas como sexualidades desviantes.

\footnotetext{
Muitas vezes eu chego no rolề e eu e a minha outra amiga, guitarrista da Gulabi, e a baterista, muitas vezes nós somos as únicas lésbicas no rolê, e sabe, por que é assim? Tem bastante gente LGBT que gosta de punk, então por quê? Cadê essas pessoas? Por que elas não vêm pro rolê? E mulheres também, pessoas negras, em vários rolês sabe, tem que levar esses questionamentos. (Caroline Rocha, baixista da banda Gulabi, 13 de jun. 2019). ${ }^{9}$
}

Além disso, apesar de importantes bandas multiétnicas integrarem o hardcore desde sua gênese, a ausência de uma estética negra é uma característica inquestionável, segun do Bessa, no artigo Racismo e Privilégio Branco no Hardcore-Punk (2014). Posto isso, Phillips (2013) faz a seguinte pergunta: "Can we talk about White Superiority and Racism in the punk?”. No texto, a autora fala de como ela passou a reconhecer que os espaços punks em que ela frequentava eram espaços "brancos". Após anos dentro do movimento ela notou que era frequentemente a única mulher negra nos eventos de punk, apesar de notar a presença de um pequeno número de pessoas mestiças. Phillips ainda explica que essa crítica não significa que as pessoas negras não estão envolvidas com a cultura punk, já que o gênero musical tem raízes no reggae, blues e rock. Porém, quando a cena é representada, ela se mostra como um território branco por excelência.

Eu acho fundamental, eu acho que esse primeiro passo, não sei se é o primeiro passo, mas esse passo da gente tocar com a gente, rolê de mina é fundamental como um lugar de identidade, onde a gente pode reconhecer a outra mulher como capaz de e a gente mesmo chegar e falar nossa eu também posso e vamos fazer, e a partir daí poderia expandir para outros espaços que também são dominados pelos homens mas que muitas vezes rechaçam as mulheres.(Julia, Guitarrista da banda Lili Carabina, 13, abr. 2019)..$^{10}$

8 O termo "rolê” é muito utilizado pelos participantes para designar os eventos nessas cenas.

9 Informação Verbal: Entrevista com pesquisadora pessoalmente. Marcas de oralidade foram mantidas.

10 Informação Verbal: Entrevista com pesquisadora pessoalmente. Marcas de oralidade foram mantidas. 
A partir dos anos 1960, as demandas de minorias sexuais e raciais, que estavam em segundo plano, passam a alcançar as esferas públicas, expressando o desejo de tornarem-se visíveis, em um esforço de autorrepresentação, questionando e criando novas práticas sociais, a partir de lutas protagonizadas por esses grupos. Como afirma Louro (2008, p. 20), é uma luta que assume diferentes faces e expressóes, que pode ser sintetizada como uma luta pelo di reito de falar por si e de si mesmo. Nesse sentido, surge nos Estados Unidos, em 1990, o movimento Riot Grrrls que se articula com as cenas punk, feminismo e empoderamento feminino, para que as mulheres tenham espaço de representar e ser representadas, utilizando da música como maior forma de expressão e comunicação de suas causas. (RIBEIRO; COSTA; SANTIAGO, 2012, p. 227).

A primeira banda de mina brasileira foi a Dominatrix, sendo esta considerada Riot Grrrl, foi fundada em 1995, formada só por mulheres, o que era muito escasso na época. $\mathrm{Na}$ matéria da revista Vice que é atualmente o maior grupo de mídia global no mundo com foco em jovens, Uma história oral do Dominatrix, feita no aniversário de 20 anos do álbum "Girl Gathering”, mostra como a banda foi muito importante para a cena de mulheres no punk, enfrentando o machismo da cena, despertando em outras mulheres a vontade de montar bandas, e até mesmo a visão de que a cena era machista e precisava de uma nova configura ção. A banda Dominatrix, influenciou o surgimento de novas bandas como Bulimia e Menstruação Anárquica, também operando em uma chave feminista e empoderadora.

Quando questionei, algumas participantes disseram não saber muito sobre esse movimento ou não fazer parte dele. Posto isso, a cena punk e hardcore de mulheres não está necessariamente relacionada com o movimento Riot Grrrl. Apesar de este ter sido e ainda ser importante para proporcionar o engajamento de mulheres em prol de uma cena feminina, influenciando inclusive a cena punk e hardcore das minas. Essa por sua vez, se coloca dentro desse espaço marcado majoritariamente por homens, para estabelecer seus discursos criticando o ambiente em questão por não validar suas pautas, utilizando do próprio aparato contido nessas cenas para tal.

Atualmente, vemos uma quantidade maior de bandas de mulheres, em um número que possibilita a realização de festivais com bandas só de mulheres, como o Lady Fest ${ }^{11}$,

11 O Lady Fest é um festival contracultural feminista com produções voltadas para a questão de gênero. Sua primeira edição ocorreu nos Estados Unidos nos anos 2000, se difundiu mundialmente e acontece em vários países, entre eles o Brasil, que teve sua primeira edição em São Paulo no ano de 2004. 
Girls Rock Camp ${ }^{12}$, Dyke Fest ${ }^{13}$ e o próprio Maria Bonita Fest. Maia, como organizadora do último festival em questão, tendo uma visão mais ampla da cena, sendo também integrante de bandas, entende que a cena feminina tem uma atuação política mais atual em detrimento da cena masculina que se manteve com opinióes e ideias desde o surgimento da cena. Com isso, a cena feminina se mostra mais ativa e efetiva nos debates sobre minorias.

\begin{abstract}
Dentro dessas cenas dos caras, tem pouca gente mais jovem e a gente percebe que nas cenas das mulheres a gente vê muita menina chegando e a impressão que dá é que a gente enquanto mina está conseguindo se reinventar mais, reinventar mais o punk e hardcore de forma que minas mais novas queiram estar e somar mais do que a cena padrão. Tipo a cena dominada por homens, parece que o poder dos caras se reinventarem é nulo praticamente, os caras meio que pararam naquela época com aquelas ideias, e politicamente não evoluíram em nada sabe, e a impressão que a gente tem é que na cena que tem minas a gente se reinventou muito mais porque a gente meio que acompanhou uma discussão política em relação ao feminismo, e nossas pautas que essa cena dominante masculina, hétero e branca não se preocupa e não tem intenção de acompanhar (Maia, organizadora do Maria Bonita Fest, vocalista da banda Gulabi, Baixista da banda Lili Carabina 18, fev. 2019). ${ }^{14}$
\end{abstract}

Conversando e até mesmo entrevistando algumas participantes desses circuitos, pude notar que elas mesmas identificam algumas problemáticas na cena comum, entre elas uma maioria de homens brancos frequentando, poucas pessoas LGBTQ+ (Lésbicas, Gays, Bissexuais, Travestis, Transexuais, Transgêneros, Queer, etc.) e dificuldade de acesso aos eventos por eles estarem em regiões centrais. Destes, consegue-se mudar a faceta de uma minoria de mulheres e LGBTQ+ na cena das minas, no entanto, a questão de raça e de acessibilidade ainda está caminhando. May, participante da cena e baterista da banda Gulabi, tem um entendimento de que os espaços da cena não estão colocados para mulheres periféricas como ela, mas que esse espaço deve ser conquistado:

Como eu sou mina de periferia, mina filha de mulher preta, mina pobre, essa cena não é pra mim, eu to aqui de teimosa, mas não é, cara basicamente o público é um

12 Um acampamento musical, presente em diferentes partes do mundo em que meninas aprendem a tocar instrumentos, formar bandas, escrever músicas, além disso, realizam uma apresentação final. No Brasil, o Girls Rock Camp ocorre em Sorocaba, São Paulo.

13 O festival lésbico feminista é idealizado e realizado por mulheres lésbicas com o objetivo de fortalecer a cena underground LGBTQI+, ocorre em São Paulo, cuja primeira edição aconteceu em 2017. A 4o edição ocorrerá no dia 31 de agosto de 2019.

14 Informação Verbal: Conversa com pesquisadora por redes sociais. Marcas de oralidade foram mantidas. 
A Cena das Minas: dinâmicas de gênero nas cenas musicais do Punk e do Hardcore em São Paulo

público branco, é um público de classe média, é de gente que mora em lugar bacana, é de gente de centro, de gente que nunca vai entender perrengue de gente pobre fudido, tá ligado? Tipo eu to porque não sei, porque sou teimosa, porque não é pra mim. Eu to aqui porque eu quero que um dia, as minas da periferia elas também sejam teimosas igual a mim, que elas também saibam que podem encontrar um lugar ali, e que a cena não precisa ficar numa bolha, em um único local, e no centro, ela pode ta na periferia também, a informação pode estar na periferia também, o que eu acho bem difícil, onde eu moro eu acho que eles nunca ouviram a palavra punk. (May, baterista da banda Gulabi, 13, abr. 2019)..$^{15}$

Das participantes entrevistadas, há um consenso de que nos eventos com bandas mais antigas da cena masculina o público será homens brancos, alguns negros, algumas mulheres e uma minoria de mulheres negras. Já um "rolê” Riot Grrrl, uma maioria de mulheres brancas e classe média. No Hardcore, homens brancos e classe média. Já na cena das minas punk e hardcore, um espaço mais plural, uma maioria de mulheres, homens e LGBTQ+. Como afirma Nina, guitarrista da banda Charlotte Matou Um Cara "o movimento punk perdeu muito a sua essência de combate e afrontamento. Nisso a cena das minas ganha disparado.” 16

Ademais, elas notam como um problema a pouca quantidade de mulheres negras. Sobre este aspecto, Maia, mulher preta, concebe que apesar de terem uma participação muito importante, talvez essas mulheres não estejam na cena por não ser um ambiente convidativo para elas, que pode inclusive afastá-las desses lugares por não as inserirem e trazer um desgaste psicológico.

Você ir em um espaço que você deveria ser acolhida, que você deveria ter uma abertura para discutir ideias antirracistas e tal e você tem que ficar se provando. Eu acho que a participação das mulheres negras na cena ela é muito importante, ela é muito desgastante. Eu entendo absurdamente uma mulher negra se ela não quiser participar, eu acho que tem poucas mulheres, têm poucas mulheres que aguentam ficar nisso e acho importante a gente criar cenas em que tenham mais mulheres negras, criar cenas entre mulheres, discutir feminismo, racismo, eu acho muito importante a participação da mulher negra mas eu também entendo que a mulher negra não queira participar em determinados espaços, tantos de espaços que só tem meninas brancas que não entendam as nossas questóes, e principalmente espaços que só tem caras que não entendem as questôes da mulher ou da mulher negra. Na real acho que o punk perde muito com a forma como ele é, tá ligado, porque não é muito atrativo assim pra gente, mas seria importantíssimo que tivesse

15 Informação Verbal: Conversa com pesquisadora por redes sociais. Marcas de oralidade foram mantidas.

16 Entrevista por email. 
cada vez mais mulheres negras nesses espaços. (Maia, organizadora do Maria Bonita Fest, Vocalista da banda Gulabi, Baixista da banda Lili Carabina, 13, abr. 2019). ${ }^{17}$

Ainda sobre a participação de mulheres negras na cena, Cah, guitarrista das bandas Bandido da Luz Vermelha, Matricis e Punbo de Mahin, afirma que "o punk é periférico, é a voz do excluído. A mulher negra culturalmente não é vista tocando ou cantando rock, e ter mos essa representatividade é essencial para fortalecer e incentivar cada vez mais minas a estarem na cena". ${ }^{18}$

Com isso, a representatividade é um elemento fundamental nessas cenas estudadas. Ao analisar a trajetória até a cena de minas, vemos como ter uma banda de mulheres no palco faz com que outras mulheres entendam que podem estar lá também. Entendem que o espaço em questão também é um local para si, em que se sente representada, e com isso, mais pessoas que se identificam vão chegando a cena, acrescentando, e participando. Ou seja, sem bandas de mulheres, sem bandas LGBTQ+, sem bandas de pessoas negras, esses espaços poderiam ainda se encontrar com a mesma configuração em que surgiram e sem discutir essas pautas minoritárias, desse modo, essas pessoas estariam fora da cena ou sendo oprimidas nesses ditos espaços.

Em entrevista com a banda Punbo de Mabin, banda punk em que todos os integrantes são negros, composta por duas mulheres e dois homens, realizada pela Unleashed Noise Records, Leandro, o entrevistador e participante da cena acredita que uma banda como a Punho Mahin, é muito importante para a cena por representar os negros:

A ideia principal que fica é que a representatividade, as pessoas pretas têm uma banda punk, que em noventa por cento embranquecido, as pessoas na maioria são brancas, e as pessoas vão ter referência agora. Eu nunca vi uma banda punk no cenário nacional formada só por pessoas pretas, então isso é representatividade forte. (Leandro, Unleashed Noise Records). ${ }^{19}$

Ainda sobre representatividade, podemos entendê-la como forma de despertar consciência, na visão das entrevistadas podemos dividir duas chaves das quais elas falaram so-

17 Informação Verbal: Conversa com pesquisadora por redes sociais. Marcas de oralidade foram mantidas.

18 Entrevista por email.

19 Entrevista com a banda Punho de Mabin. Publicado em 2, abr. 2019. Disponível em: <https:// www.youtube.com/watch?v=YVs7RFLS2BA>. 
bre representatividade com relação a banda de mulheres. A primeira delas, como a escassez de bandas de mulheres em certo momento fizeram com que elas tardassem para entender que poderiam participar da cena, tocando, cantando, fazendo festivais, zines, etc., pois não havia um referencial para isso, pois a cena era formada majoritariamente por homens. E também, o contato com bandas femininas que surgiram e as influenciaram a ver a cena de outra forma, e ter vontade de participar mais ativamente. Pogs, guitarrista da banda Gulabi, descreve como foi se identificar como mulher lésbica que fazia parte dessa cena masculina:

Eu por exemplo para me identificar no rolê como mina, sapatão demorou, ficava por ser um som mais diferente, por ser uma coisa mais suja que casava mais com as minhas ideias, mas até eu me ligar "Putz, cadê as minas sapatão daqui?”, sabe?! Hoje em dia é o tipo de coisa que eu não consigo mais desver assim. Inclusive, hoje em dia a gente cola no rolê, e você vê que não tem mina já dá uma brochada... Daí você vê que só tem gente hétero, daí você também fica meio assim. E aí com as pautas mesmo que a gente discute na banda querendo ou não acrescenta bastante as sim na minha vida. Às vezes eu colo no rolê “Só tem gente branca aqui, né?!”. Sabe tá meio errado isso aqui, então, se pensar mais nisso você acaba vendo que tá difícil. (Pogs, guitarrista da banda Gulabi,13, abr. 2019). ${ }^{20}$

A banda Sapataria, formada por mulheres lésbicas, surgiu de uma ideia de representatividade lésbica, abordando em suas letras questões do cotidiano de mulheres lésbicas, como afirma a guitarrista da banda:

\footnotetext{
Quando pensei em formar uma banda de lésbicas e chamei a Dan minha ideia era ter mais representatividade na cena. Já existiam muitas bandas com integrantes lésbicas, mas eu particularmente demorei muito tempo para ter contato com elas isso por conta do machismo que me fez priorizar bandas masculinas durante anos. A partir do meu contato com a militância lésbica me dei conta da importância de gerar mais visibilidade sapatona e coloquei como meta fazer com que todos os meus projetos pessoais tivessem como princípio ser por e para lésbicas, a banda foi uma extensão desse desejo. A Sapataria para mim é a banda que eu precisava ouvir quando estava me assumindo para os meus pais, lidando com meus conflitos em relação a sexualidade e abandonando a feminilidade. A importância é fazer um som de sapatão para sapatão trazendo representatividade e fazendo com que aquela fancha da plateia possa de alguma forma ver seus conflitos no palco. (Marina Garcia, Guitarrista da banda Sapataria, 21 jun. 2019). ${ }^{21}$
}

20 Informação Verbal: Entrevista com a pesquisadora pessoalmente. Marcas de oralidade foram mantidas.

21 Entrevista por e-mail. 
Quando perguntei se a banda em questão já sofreu algum comentário desagradável enquanto banda LGBTQ+ e/ou enquanto participantes da cena, a guitarrista respondeu que após o show da Pussy Riot, que elas realizaram no dia 20 de abril, alcançaram uma visibilidade além da bolha feminista e lésbica, e com isso, apareceram comentários negativos em algumas redes de mídias, pessoas ofendendo a sexualidade das integrantes da banda. Além disso, Isa Medeiros, baterista da mesma banda diz que há pessoas que entendem que a banda se posiciona como lésbica como forma de impulsionar público:

Eu já ouvi que a banda está usando o lesbianismo "pra se promover". Gostaria muito de perguntar a pessoa que fez esse comentário em que mundo o rótulo "lésbica" dá VANTAGEM às mulheres, sinceramente! Mas nem falei nada, ela não parecia muito aberta a uma conversa tranquila. (Isa Medeiros, Baterista da banda Sapataria, 21, jun. 2019). ${ }^{22}$

No evento que ocorreu dia 13 de abril, em que estreou a demo da banda Lili Carabina, "Pistolar y Pogar", arrecadando também, brinquedos para a Biblioteca Comunitária Espaço do Saber, tive a oportunidade de conversar com a Madu, que estava pela primeira vez em um evento de punk e hardcore, mas que já vinha como participante da cena de rock, ela diz:

O que eu senti foi a forma intensa que as músicas são cantadas, me remete a algo relacionado a protesto e as letras com mensagens diretas sem muita enrolação, é o tempo necessário para passar aquela mensagem e pronto. Eu não achei algo diferente, porque não era totalmente desconhecido. Mas o que me chamou muito atenção, é a forma como as pessoas dançam, e falam sobre o que é ser punk, e por que ser. As visões são diferentes e iguais ao mesmo tempo, pois cada um vive uma realidade diferente, mas o intuito de estar ali pela cena e porque estar ali é bem igual e achei isso bem importante. Pra mim é algo que fortalece ainda mais! (Maria Eduarda Damasco, 13, abr. 2019). ${ }^{23}$

Assim, a cena das minas está crescendo, mais bandas novas surgem, e inspiram outras garotas a fazerem suas próprias músicas, montarem suas próprias bandas, chegando in clusive a meninas que não participam das cenas, mas de cenas semelhantes e acabam por encontrar nesses espaços algum tipo de identificação.

22 Entrevista por e-mail.

23 Informação Verbal: Retirada de conversa com pesquisadora. 
A cena das minas punk e hardcore em São Paulo se forma no bojo das estruturas machistas da cena comum como um eixo que abrange as mulheres da cena, cuja participação assume um lugar de protagonismo tanto na organização de eventos e festivais quanto na formação de bandas, na criação musical, na publicação de fanzines, o que contribui para a maior difusão e evolução da cena. O que anteriormente era a normalidade, homens à frente nos shows, festivais, nas rodas de pogos ${ }^{24}$, etc., hoje se encontra com mulheres à frente, afirmando, contestando, representando no espaço subversivo dessas cenas.

Deve-se ressaltar, que a cena das minas não é fechada, inclusive eventos mistos são realizados. O próprio "Pistolar Y Pogar” citado anteriormente, contava com a presença de bandas formadas por homens e mulheres. Retomando a fala da Cibele, organizadora do Maria Bonita Fest, vocalista da banda Gulabi: "a gente não proíbe que homens participem, mas eles têm que saber qual é o lugar deles que definitivamente não é na frente, as mulheres são na frente”, entendemos que é uma crítica que deixa claro que a questão está em torno de como se estrutura a cena comum, e não há uma oposição direta à presença dos homens em si.

Por consequência, o crescimento da cena das minas influencia o questionamento sobre onde estão as minorias, mulheres, negras e LGBTQ+, e faz com que a cena punk e hardcore evolua como um todo. Mesmo que essas minorias estejam sendo representadas na cena das minas, com bandas feministas e festivais feministas, antirracistas, antifascistas e próLBGTQ+, quando colocadas em eventos mistos esses discursos repercutem, atingindo um público que talvez tenha uma identificação maior com essas questões, que nem sempre estiveram presentes nesta cena punk hardcore mais tradicional. Contudo, são demandas que se encontram agora melhor representadas, especialmente a partir da crescente presença e importância de bandas de mulheres, incluindo mulheres negras e LBGTQ+, que têm desenvolvido estratégias significativas para questionar a hegemonia heteropatriarcal branca tradicionalmente presente na cena, afirmando suas próprias diferenças.

24 Pogo é um estilo de dança de origem africana que historicamente se tornou associada à cena do mundial. 


\section{REFERÊNCIAS BIBLIOGRÁFICAS}

BESSA, R. Racismo e Privilégio Branco no Hardcore-punk. Medium, 2014. Disponível em: https://medium.com/@rafaelxvx/racismo-e-privilegio-branco-no-hardcore-d34ec6fb18f6. Acesso em: 31 jul. 2018.

BIVAR, A. O que é punk. São Paulo: Brasiliense, 1982.

CAIAFA, J. Movimento Punk na Cidade: A invasão dos bandos sub. Rio de Janeiro: Jorge Zahar Editor Ldta, 1985.

CSAPO, A. P. BELAS DONAS: Meninas Na Cena Punk. 2004, 19 min.

FILHO, J.C.; JANOTTI JUNIOR, J. A música popular massiva, o mainstream e o underground- Trajetórias e caminhos da música na cultura midiática. Intercom - Sociedade Brasileira de Estudos Interdisciplinares da Comunicação XXIX Congresso Brasileiro de Ciências da Comunicação, UnB, p. 1-14, set, 2006. Disponível em: http://www.intercom.org.br/papers/nacionais/2006/resumos/R1409-1.pdf. Acesso em: 15 jul. 2018.

GUMES, N. V. C. Música - marcas sonoras juvenis. In: XXVII CONGRESSO BRASILEIRO DE CIÊNCIAS DA COMUNICAÇÃO. Porto Alegre, Intercom, 2004. Disponível em: http://www.portcom.intercom.org.br/pdfs/ 154695334944210728619242571716276375905.pdf. Acesso em: 17 ago. 2018.

JANOTTI JUNIOR, J. S. Entrevista - Will Straw e a importância da ideia de cenas musicais nos estudos de música e comunicação. Revista da Associação Nacional dos Programas de PósGraduação em Comunicação/ E-compós, Brasilia, v. 15, n. 2, mai./ago. 2012. Disponível em: http://www.e-compos.org.br/e-compos/article/view/812. Acesso em: 31 jul. 2018.

JUNIOR, D. S.; ROSSETTI, R. Distorções midiáticas do movimento Punk em tempo de autoritarismo político. Revista do Programa de Pós-graduação em Comunicação, UFJF, vol. 9, n. 2, p.1-20, dez, 2015. Disponível em: http://ojs2.ufjf.emnuvens.com.br/lumina/article/view/ 21197. Acesso em: 30. Jan.2019 
KEMP, K. Grupos de estilo jovens: O "Rock Underground" e as práticas (contra) culturais dos grupos "punk" e thrash" em São Paulo. Unicamp, dez. 1993.

LOURO, G. L. Gênero e sexualidade: pedagogias contemporâneas. Pro-Posições, online, v. 19, n. 2, p. 17-23, mai./ago. 2008. Disponível em: http://www.scielo.br/pdf/pp/v19n2/ a03v19n2.pdf. Acesso em: jul. 2018.

MARQUES, G. M. As artes de resistir: mulheres na cena anarcopunk (1990-2002). XXVIISIMPÓSIO NACIONAL DE HISTÓRIA- CONHECIMENTO HISTÓRICO E DIALOGO SOCIAL, Natal, p. 1-16, jul. 2013. Disponível em: http://www.snh2013.anpuh.org/resources/anais/27/1364774184_ARQUIVO_TextoAnpuh-marques.pdf. Acesso em: 15 jul. 2018.

MÉLlO, R. P. Corpos, Heteronormatividade e Performances Híbridas. Psicologia E Sociedade, Belo Horizonte, v. 24, n. 1, p. 197-207, jan./abr. 2012. Disponível em: http://www.repositorio.ufc.br/handle/riufc/19382. Acesso em: 12 ago. 2018.

MOREIRA, G. BOTINADA: A origem do punk no Brasil. 2006, 110 min.

NETO, N. T. Enterrado Vivo: Identidade punk e território em Londrina. São Paulo: Editora UNESP, 2004

PHILLIPS, S. Can we talk about white superiority and racism in Punk?. The Multicultural Politic, 2013. Disponível em: http://www.tmponline.org/2013/09/03/race-punk-music/. Acesso em: 01 ago. 2018.

RIBEIRO, E. Uma História Oral do Dominatrix. VICE, 2017. Disponível em: https:// www.vice.com/pt_br/article/vbb7ey/dominatrix-historia-oral

RIBEIRO, J. K. A.; COSTA, J. C.; SANTIAGO, I. M. F. L. Um jeito diferente e "novo" de ser feminista: em cena, o riot.grrrl. Revista Ártemis, Edição V. 13; p.222-240, jan./jul, 2012. Disponível em: http://www.periodicos.ufpb.br/index.php/artemis/article/viewFile/ 14226/8154. Acesso em: 28, jan, 2019. 
SHRODES, A. The 'Race Riot' Within and Without 'The Grrrl One'; Ethnoracial Grrrl Zines' Tactical Construction of Space. The Department of English University of Michigan, 2012. Disponível em: https://deepblue.lib.umich.edu/handle/2027.42/96647. Acesso em: 27 fev. 2019.

Unleashed Noise Records: Entrevista 05 - Punbo de Mahin. 2018, 38 min. Disponível em: https://www.youtube.com/watch?v=YVs7RFLS2BA.

URIARTE, U. M. O que é fazer etnografia para os antropólogos. Ponto Urbe Revista do núcleo de antropologia urbana da USP, online, n. 11, p. 1-14, 2011. Disponível em:https://journals.openedition.org/pontourbe/300. Acesso em: 23 jul. 2018.

VIEIRA. T. A defesa da legitimidade suburbana do punk nacional nos estudos da década de 1980. Revista Sapiência: Sociedade, Saberes e Práticas Educacionais - UEG/Campus Iporá, Goiás, v.5, n.2, p.109-122, ago./dez., 2016. Disponível em: http://www.revista.ueg.br/index.php/sapiencia/article/view/5938/4122.Acesso em: 25 jan. 2019.

WELLER, W. A presença feminina nas (sub)culturas juvenis: a arte de se tornar visível. Rev. Estud. Fem, Florianópolis, v. 13, n. 1, p. 107-126, abri. 2005. Disponível em: http://www.scielo.br/scielo.php?script=sci_arttext\&pid=S0104-026X2005000100008\&lng=en\&nrm=iso. Acesso em: 23 jan. 2019. 